spoken of, they do require preoperative and postoperative medical treatment. At least three of the men present who are doing a large number of goiter operations have a printed outline as to follow-up treatment of patients after they return to their homes. Follow-up care of these people with hearts more or less crippled, and who always will be more or less crippled, is of special importance, in order to put them in the best condition possible. They feel well enough, but unless they are taken care of and take care of themselves, they do not get along very well. Dr. Crile and Dr. Mayo emphasized the fact that goiter is a surgical disease. A very distinguished physician, Dr. Osler, emphasized this point twenty years ago when he said that, after the patient has been unsuccessfully handled for three months, he should be referred to the surgeon. Another point which deserves to be mentioned in this connection is that no matter how simple and how safe the proposition may seem, a man must be prepared to handle almost anything, when he goes into the neck of a patient with goiter. We are not able to tall always when we are going to encounter malignancy, or deep thoracic goiter, or when the toxemia may be a very much graver element than seems at first.

DR. J. EARL ELSE, Portland, Ore.: I want to emphasize two things: first, I hope that no one goes away with the idea that all goiter cases are surgical cases. The majority of cases do not require surgical treatment. Colloid goiters, for the most part, are not surgical cases, and only rarely does a goiter patient in the adolescent age require operation. Goiter accompanied by hyperthyroidism, however, is another matter. The toxic exophthalmic goiters are practically all surgical. The other thing $I$ wish to mention is the relationship of tonsillitis to goiter. If tonsillitis is a direct etiologic factor in goiter, I do not understand why the majority of cases appear in females, because there are probably more cases of infected tonsils in the male than in the female. In view of this fact, it would appear that the relationship, if there be one, is an indirect one. Personally, $I$ am inclined to think that at least in the majority of cases, the relationship is merely coincidental.

\section{PROGRESS IN CARE AND EDUCATION OF CRIPPLED CHILDREN IN OHIO UNDER NEW LAWS *}

\section{BURT G. CHOLLETT, M.D. TOLEDO, OHIO}

The present movement for the care and education of crippled children in Ohio had its beginning six years ago in a very small way in one clinic. A recently formed Rotary Club was looking for some worthwhile work, and its attention was drawn to a particularly sad cripple with prenatal amputation of both arms at the elbow, one leg above the knee, and the other leg and ankle very much distorted, with some bones missing. He was then 12 years old and had never been to school. Following the suggestion of an orthopedic surgeon that the boy would eventually need some surgery, but at the present time it would be better to start his education, he was sent to another city in which his education was started. Later an operation was performed, the patient was given artificial limbs, and now he is self-supporting.

In this locality there was a small dispensary maintained by a district nurses' association. The Rotary Club became very much interested in the orthopedic clinic at the dispensary, and secured for us a brace fund. Interest in this work grew from year to year,

* Read before the Section on Orthopedic Surgery at the Seventy. Third Annual Session of the American Medical Association, St. Louis, May, 1922 . the local club furnished a special fund of several thousand dollars each year for the care of cripples and later a special school was started for children unable to attend the regular school. Transportation was furnished, and later a warm lunch was served each day.

A great deal of publicity was given this work throughout the state, and as a direct outcome there was a bill passed by the legislature and an appropriation made to establish a state hospital school for cripples; but the actual starting of building was delayed by the war. In the meantime, several Rotary clubs became interested in the crippled work in their community, and in order to interest other Rotary clubs in Ohio in this work a society was formed, originally of Rotarians, to help crippled children, as a special phase of Rotary work. This society was called the Ohio Society for Crippled Children.

"The object of this society is to create state-wide interest and, by cooperation, aid the state-wide survey and holding of clinics,. aiding in adding beds to the present hospital facilities and to aid in the passage of legislation to provide for physical, mental and vocational education and publicity."

One of the first things done was the ascertaining of what was being accomplished in other states. It was found that the majority of state hospital schools for cripples were politically dominated, that they were inadequate in bed space, that their chief field of usefulness was in the immediate surrounding area of the hospital, and that very few cases came from a radius of more than 40 or 50 miles.

Ohio, with a population of $6,000,000$, had approximately, according to the figures of other surveys, more than 12,000 crippled children, and one central institution would be a very inefficient approach to the problem.

Ohio had, at that time, three orthopedic clinics organized and functioning in the northern part of the state, one in the center of the state, and two in the south. It soon became evident that the building of a central hospital school, such as exists in many other states, would not meet the problem. So a plan was suggested to enlarge the existing six orthopedic clinics in the state and probably organize two or three new areas, making eight or nine in all. By this method several communities would have centers, smaller than a large central hospital, locally controlled, with much local interest, and the facilities for the care of crippled children would be brought near to the child, avoiding the taking of the child a great distance and out of contact with relatives and home, and the responsibility for the care of cripples would be borne, to a great extent, locally. This plan also offered a more speedy solution to the problem. After a survey of all existing laws for the care of cripples in all of the states had been made by the Department of Labor at Washington, a new law, with the aid of several of the leading attorneys and law makers, was formed and passed about two years ago and is known as House Bill 174.

It was apparent very early in this work that a large number of the neglected deformities were in isolated areas or in the rural districts, and many parents would be financially unable to bear the burden of cure and education and they would be unwilling to allow these children to go any great distance from home. The law was so worded that it permitted the state to take as wards dependent children requiring surgical care. It also made mandatory their care, if necessary. As no 
state funds were available for this purpose and probably would not be appropriated in large amounts, the law was so worded that it allowed the division of charities to pay the current bills in the care of these children from a special fund for this purpose, and to charge this amount back to the county from which these children came.

About the same time, the state department of education was given power, by a new bill known as House Bill 200, to establish special schools in any locality in which eight cripples could be assembled. The local board of education is obliged to provide the school room and spend a per capita amount equal to the amount spent on normal children, to which the state department of education is to add an amount up to $\$ 300$ for each child each year. To this may be added $\$ 250$ per capita for boarding if a child is outside the jurisdiction of the local board of education. With this fund available, transportation and hot lunches can be supplied and a special teacher can be provided for any such school. This law further provides for instruction in the home of children who cannot be transported to a school.

As the enforcement of laws depends on the popularity of the law and the wishes of the community, a regular campaign to care for and educate cripples was begun and has been carried on for the last three years by all the Rotary clubs in Ohio, numbering forty-eight, with a membership of more than 4,000 composed of representative business and professional men in their respective communities, and the influence of this body of representative citizens has been great.

It was early apparent that there were many agencies, both official and private, having some contact with this work, and that some sort of representative committee must be established to coordinate the activities and to get the cooperation of all, with the result that an advisory state council for the handicapped was formed, composed of a representative from these official agencies: the state board of health, state department of public welfare, state department of education, state department of vocational education and department of industrial relations; also a representative from these private agencies: Ohio Medical Association, Ohio Hospital Association, Ohio Society for Crippled Children, Ohio Institute for Public Efficiency, Ohio Public Health Association and Ohio Red Cross.

The purpose of this council was "to serve as a clearing house among the public and private state-wide agencies in Ohio concerned with the welfare of the handicapped and by discussion and advice to develop cooperation among them."

The Ohio Institute for Public Efficiency effected the organization of all these interested agencies, and has since been most helpful in supporting the individual agencies and coordinating and directing the combined effort of all these varied activities as they pertain to crippled children.

The next important step was the formation of the professional advisory committee, composed of five orthopedic surgeons, attached to the division of charities of the department of welfare. The function of this committee is to assist in passing on the qualifications of surgeons and hospitals caring for this type of case. It was realized that it was most important to have the helpful cooperation of all medical men, especially of all the orthopedic surgeons and agencies interested in this particular work, and to fix high standards and to help safeguard the patient, hospital and surgeon.

The popularization and the spread of this work over the state was very rapid, and the number of beds offered was as great as could be efficiently handled, so thist an effort has been made to keep the difficult surgical cases in the hands of orthopedic surgeons of known experience and judgment.

Instead of making a social service survey per se, it was decided that a survey be made in the form of a diagnostic clinic similar to the tuberculosis clinics that have previously been held, and a number of clinics have been held following the suggestion that the facilities be taken to the child. Forty-four clinics were held during the first nineteen months, and about 2,500 children were examined. Most of these clinics, following the suggestion of the board of health, were held in rural counties rather than in the already established orthopedic centers, these counties having no special hospital facilities or specialized medical men.

The rules for handling the clinics and the departments interested are:

1. Supervision of the clinic is under the bureau of child hygiene of the state health department, and cripples of all ages and all social classes are examined, through the local health commissioner and the county medical society with the help of known orthopedists as consultants.

2. The division of special classes of the state department of education handles children aged from 6 to 18 , and organizes and advises special public school classes for crippled children, admitting children not now in school and those who would be better off in special rooms-those with crutches, braces, casts, bone tuberculosis, etc.

3. The division of civilian rehabilitation handles adults over 16, places in training handicapped adults over 16 and through the seventh grade, injured from birth, by disease, by accident or by injury. "Such adults must have ambition, and their physical condition and employment object justify the training." Funds for this department are supplied by special federal act which grants an amount equal to the amount raised in the state for this purpose.

4. The children under 18 who can be benefited by treatment and whose parents cannot or will not furnish such treatment may be committed by the judge of the juvenile court to the child's bureau of the department of welfare, which assumes guardianship and supervises the child's care in whatever hospital of the state it sees fit to place the child. Hospital bills, surgeons' fees and bills for special examinations, braces, etc., are paid for and charged back to the county from which the child came.

Most diagnostic clinics, following the suggestion of the board of health, have been organized through the local health commissioner and the county medical society, private agencies, Rotary, Kiwanis and Exchange clubs, the Red Cross, the federation of charities, judge of the juvenile court, county school superintendents and county commissioners affiliating, to support and aid in the actual holding of the clinic, together with representatives from the foregoing departments.

Since the first object of the clinic is to furnish an expert diagnosis, the medical agencies are the primary ones interested; but it seems logical to make the clinic 
also a clearing house for all the problems in the educational and vocational training and treatment of cripples.

A survey of cripples is sometimes made before holding the clinic, but this is not necessary, as experience has indicated that proper advertising brings in more cases heretofore unknown than the number so laboriously hunted out. Such individual efforts would be better spent after the clinic in the follow-up work. Cripples of all ages should be invited, as vocational training is available for the adults. The clinic is usually held in the courthouse and, if possible, on the regular meeting day of the county medical society, with the consulting orthopedist available to address the meeting. Records are taken of the diagnosis in each case and given at the time to the parents; copies are also made for the medical authorities and the medical members of the private agencies which afe to help in the followup work.

The people able to pay for services plan with their own physician for the treatment, but indigent cases will be followed by the county nurse to see that state provisions or private relief are made available. After the clinic, the work is carried on locally. The clinic is of little value without intelligent follow-up work, and here is the great field for the private agencies, chief among which is the Ohio Society for Cripples.

One of the striking results from some of the early clinics held in rural districts was a strengthening of the position of the health officer, health nurse and school nurse, the establishment of local clinics and the enlarging of the local health activities.

The special schools for cripples in the state have grown until there are, at present, special schools in eleven cities with an attendance of 400 ; ten other cities are in the process of such organization. Approximately 300 indigent cases have been cared for through the state departments; the exact number of private cases is not available, but is probably greater. In one clinic that was held, 120 children were examined, and the condition of nose, throat, chest, teeth, nervous system and deformities was recorded, with diagnosis and outline of treatment. Every member of the local Rotatry Club of 100 either drove his own car or furnished a driver for the day, was made responsible for at least one child to and from the clinic, and agreed to hold himself ready to transport the same child, at any time during the year, to the hospital for after-treatment.

The influence of private agencies in aiding in the formation and organization of the present plan in carrying out the follow-up work has been of inestimable value. The most active single agency is the Ohio Society for Crippled Children, composed of representatives from forty-eight Rotary clubs in forty-eight separate communities with a membership of more than 4,000. It has sponsored this work from the beginning, and has made it the chief work of the organization in Ohio.

Similar agencies have been formed in the Rotary clubs of New York and Michigan, with Kentucky, Tennessee, Indiana, Illinois and Ontario making inquiry and anticipating organization.

The interest and enthusiasm shown in these states led to the formation of the National Society for Crippled Children in December of last year; and, by the admission of the Province of Ontario, Canada, an international society has now been organized. The object of this society is to interest the 1,000 Rotary clubs, with more than 76,000 members, in twenty countries, in this work.

The week of May 8, the birthday of Mr. Edgar Allen, the active organizer of this crippled children's work in Ohio and president of the Ohio Society for Crippled Children, was set aside by proclamation of the governor of Ohio, to be designated as Crippled Children's Week; every Rotary club gave a special program featuring the work of crippled children and much newspaper publicity was given this work.

The main activity of the future will, of necessity, be the care of convalescent cripples, the carrying out of treatment, education and vocational and occupational training. The establishment of convalescent homes, rather than the enlargement of hospital facilities, is being planned. An effort is being made now to combine with the present facilities at hand all interested agencies, and to centralize and aid in the distribution of all bequests, legacies and special fraternal funds, to the end that the smallest amount of money may be spent for monumental edifices and that the greatest ultimate good to the child may be accomplished.

Another recent innovation has been the establishment of a liaison office in Columbus by the Ohio Society for Crippled Children, so that the private agencies can have closer contact with the state departments.

I feel that the success of this movement, which may eventually circle the globe, depends on medical guidance and, specifically, on the guidance and energy of the orthopedic surgeons. This paper was written that orthopedic surgeons may have first hand information of the present status of the movement and, by their criticism and suggestions, aid in constructing, perfecting and directing this movement, as it spreads, so that it may remain nonpolitical, nonsectarian and medically controlled, to accomplish the greatest good to the greatest number of cripples; also to stimulate more widespread interest in the scientific cure of deformities.

421 Michigan Street.

\section{ABSTRACT OF DISCUSSION}

Dr. Robert B. Cofield, Cincinnati: The principal feature of the work done in Ohio has been bringing facilities to the child. Of course, that is not possible in the less thickly populated states or where clinics and hospital treatment are not as plentiful as they are in Ohio. We have a number of good hospitals in our state and a number of good orthopedic surgeons to do the work. It seems to me that we can cure many more of these children by going to them instead of having them come to us or leaving them in state hospitals. Another thing is a state-wide survey. As Dr. Chollett says, it is very nearly impossible to hunt out these cases, but if diagnostic clinics are held and if they are advertised in the local papers, the parents will bring in the children for diagnosis and to ascertain what can be done. These diagnostic clinics are held in towns in which there are no orthopedic clinics, in the smaller towns or in the county seats. The Rotary Club is usually the prime mover in this affair, seeing to it that the children come. A record is made of the diagnosis, and the work is followed up through the Red Cross and other agencies. I think an advisory committee is very importanit in directing these cases into the hands of competent orthopedists. There is a tendency for every man who has ever seen an orthopedic operation to say, "Yes, I can do that ; send the case to me." Most practitioners are willing to attempt any kind of work, whether they can do it or not. The work of the advisory committee is to look into the qualifications of every man doing this work in the state, and the various state agencies refer the child to the proper man to do the work. 